\title{
A Novel Single Stage Push Pull Converter with Integrated Magnetics and Ripple-free
}

\section{Input Current}

\author{
Rong-Tai Chen \\ Department of Electrical \\ Engineering, National Taiwan \\ University, Taipei, Taiwan. \\ Email: rtchen@ipmc.ee.ntu.edu.tw
}

\author{
Yung-Yaw Chen \\ Department of Electrical \\ Engineering, National Taiwan \\ University, Taipei, Taiwan. \\ Email: yychen@ntu.edu.tw
}

\begin{abstract}
This paper presents a novel single stage push-pull boost converter with a improved integrated magnetics and ripple-free input current. It is found that the push pull converter when the duty cycles greater than $50 \%$ can simplify the front of boost-type converter to a novel single stage converter. Coupled inductor techniques provide a method to reduce the converter size and weight and achieve ripple-free current. All the magnetic components including input filter inductor and step-down transformer are integrated into a single EI core. The prototype is built to demonstrate the theoretical prediction.
\end{abstract}

Index Terms-coupled inductors, single stage, integrated magnetics, ripple-free, push-pull boost converter.

\section{INTRODUCTION}

In recent years, a number of single-stage input current shaping converters have been introduced in [1]-[5]. It is found that many of these topologies can be implemented by combining a two-terminal or three-terminal boost input current shaper cell with DC-DC converter along with an energy storage capacitor in between. The major disadvantages of the conventional two-stage conversion approach are the added cost and the complexity of the twocontrol loop, two-power-stage nature. The single-stage PFC $\mathrm{AC} / \mathrm{DC}$ converters that integrated the two power stages into one, thus reducing significantly the component count and cost, have gained much attention in many low-power applications during the past ten years.

In a general sense, the two main switches of push-pull converter operate alternately, with conduction duty cycles of $50 \%$ during one complete switching cycle. Conduction overlap of primary switches causes high current spikes during such intervals. In this paper, an improved boostderived push-pull converter is proposed. It is found that the push pull converter when the duty cycles grater than $50 \%$ can simplify the switch of the boost-type converter. Thus, the input current shaper and the push pull converter are integrated together to one single stage. One of the advantages of the overlapping primary switch conduction is the equal division of the inductor current in two switches, thus reducing their average and rms current levels as well as the primary winding rms current magnitude.

An application of the zero-ripple technique to converter structure is described in [6]. For a basic consideration it seems to be perfect that only by extending a basic converter structure by a defined magnetic coupling of the input and filter inductors a complete eliminiation of the input current ripple can be obtained. Coupled inductor techniques supply a method to reduce the converter size and weight and achieve ripple-free current. In order to improve efficiency and reduce size, this paper proposes an improved push-pull boost converter with an integrated magnetics. In this structure, all the magnetic components including input inductor, input filter inductor and step-down transformer are integrated into a single EI core.

This paper is organized as follows. Section I introduces the research background and the motivation of this work; Section II briefly reviews basics considerations; Section III proposed an improved push-pull boost converter with integrated magnetics ; Section IV provides experimental results.

\section{PRELIMINARY CONSIDERATION}

In order to clearly explain the proposed converter, we want to consider the primary concepts in the following.

\section{A. Single stage}

There are several interesting single-stage solutions in the state of the art [1]-[5]. Figure 1 shows the pre-regulated DC-DC boost converter with a parallel DC transformer. The switching power circuit (SPC) uses three main switch elements. The two converters are controlled independently to achieve output voltage regulation. The duty cycles of the switches S1, S2, and S3 are D, 50\%, and $50 \%$ respectively. The duty ratio $\mathrm{D}$ may be larger or less than $50 \%$.

If the duty cycles of S2 and S3 are made variable and always greater than $50 \%$ i. e. if S2 and S3 have overlapping conduction interval then $\mathrm{SI}$ is no longer needed and it can 
be eliminated as shown in Fig. 2.

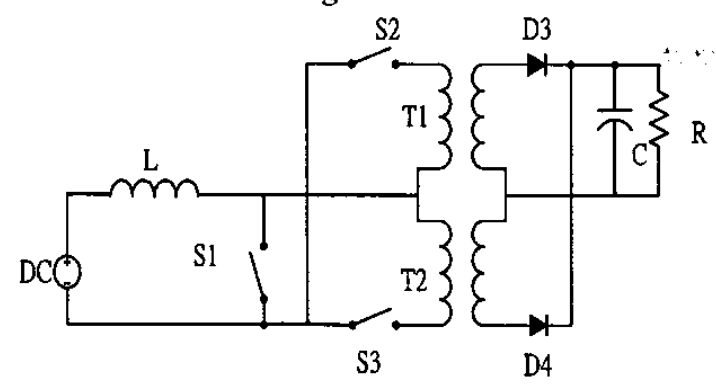

Fig. I Pre-regulated DC-DC boost converter:

One of the advantages of the overlapping primary switch conduction is the equal division of inductor current between S1 and S2, thus reducing the switch stress and improving conversion efficiency. The proposed push pull boost converter in Fig. 2 with the duty cycles greater than $50 \%$ is a suitable approach for ripple-free input current. This will be verified in the following sections.

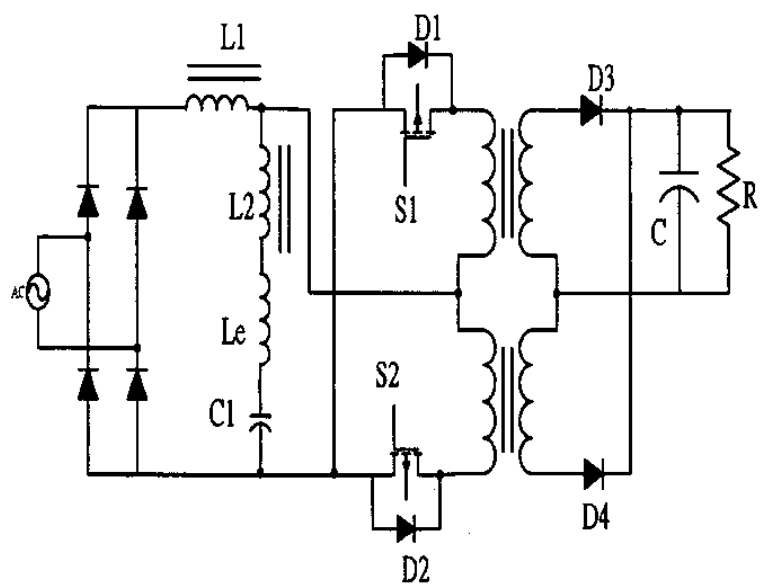

Fig. 2 The proposed push-pull boost converter

\section{B. Zero-Ripple Phenomenon}

In order to explain the effect called zero-ripple phenomenon in [6], we want to consider briefly the relationships given for magnetic coupling of the two ports networks shown in Fig. 3. Fig. 3(b) is the equivalent circuit of Fig. 3(a). The elimination of ideal transformer from Fig. 3(b) results in the simple model of Fig. 3(c). The following mathematical model is used to analyze the ripple cancellation.

Let us now make the assumption that is possible to reduce the value of $i l$ to zero in our model of Fig. 3(c), and then examine the circuit currents and voltages that result from our assumption. If $i$ il zero, then the $\mathrm{AC}$ voltage drop across Ll must also be zero, as illustrated in Fig. 3(a).

These conditions lead to the simplified circuit model of Fig.3(c), where:

$$
\begin{aligned}
& \frac{N 2}{N 1} V 1=\left(\frac{N 2}{N 1}\right)^{2} L_{M} \frac{d i 2}{d t} \\
& V 2=L e \frac{d i 2}{d t}+\left(\frac{N 2}{N 1}\right)^{2} L_{M} \frac{d i 2}{d t}
\end{aligned}
$$

Combining Equ.(1) and (2) by the elimination of the common $\mathrm{di} 2 / \mathrm{dt}$ factor gives:

$L e=\left(\frac{N 2}{N 1}\right) L_{M}\left(\frac{V 2}{V 1}-\frac{N 2}{N 1}\right)$

The relationship between secondary leakage inductance and that of the core material set by Eq.(3) is important and worth dwelling on for a moment. First of all, recall that this equation was derived based on the premise that no input ripple current existed in our model and, if satisfied, must produce this condition.
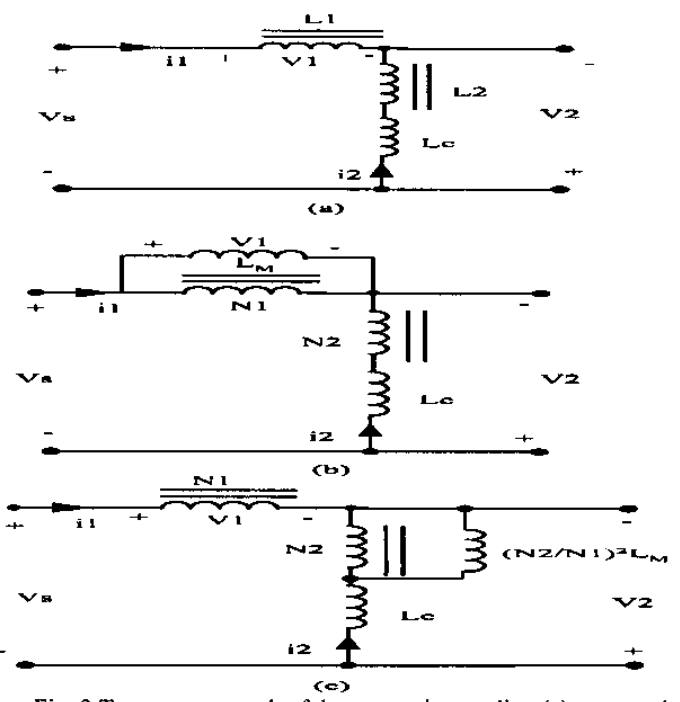

Fig. 3 Two-port network of the magnetic coupling (a) proposed coupling inductor. (b) equivalent circuit of (a). (c) equivalent circuit of (b)

\section{Integrate magnetic}

The SPC circuits of Fig. 4 are discreted magnetic versions of boost and push pull topologies with transformer isolation, let us now see if we can formulate an easy way to synthesize an integrated magnetic version of Fig.5. To begin, we must first reconstruct the circuit schematics of Fig.4 so as to detail the magnetic aspects of the transformer and inductor components. The schematics the result from this reconstruction process are illustrated in Fig. 5 Next, for each of the switching intervals of the converters, a set of equations defining the rate of change of flux in each magnetic component is established [12].

Thus, for the converter of Fig.4 during interval I (S1,S2 ON)

$$
\dot{\phi}_{L}=\frac{d \phi_{L}}{d t}=\frac{V_{s}}{N_{L 1}}
$$

For the converter of Fig.4 during interval II (SION ,S2 Off) 


$$
\begin{gathered}
\dot{\phi_{L}}=\frac{d \phi_{L}}{d t}=\frac{V 1}{N_{L 1}}-\frac{V s}{N_{L 1}} \\
\dot{\phi}_{T}=\frac{d \phi_{T}}{d t}=\frac{V_{o}}{N_{S 1}}=\frac{V 1}{N_{P 1}}
\end{gathered}
$$

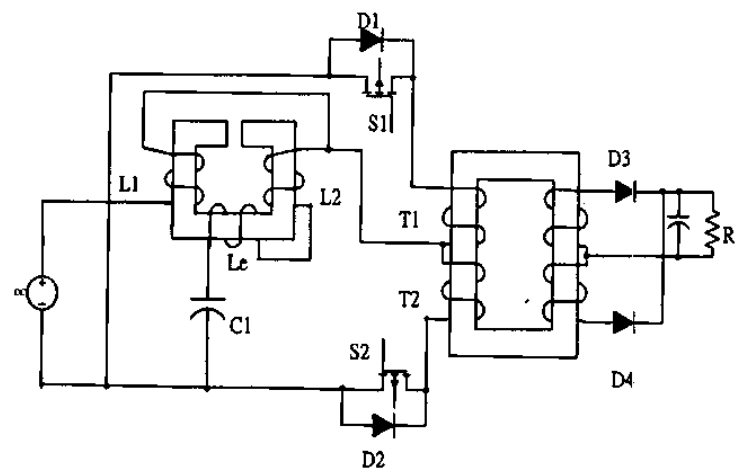

Fig. 4 Discrete magnetics of the proposed push-pull converter

From Eqs. (5) and (6), we can combine them to eliminate the dependent variable,V1. Performing this combination gives:

$$
\dot{\phi}_{T}=\dot{\phi_{L}}\left(\frac{N_{L 1}}{N P 1}\right)+\frac{V_{S}}{N P 1}
$$

Since our goal is to make the inductor a part of the same magnetic assembly that contains the transformer component, it is logical to assume that $\mathrm{N}_{\mathrm{L1}}$ should be made equal to $\mathrm{N}_{\mathrm{P} 1}$, so that all of this flux change is contained within one magnetic path or leg of this assembly. Therefore, we arrive at an expression for $\phi_{T}$ as :

$$
\dot{\phi}_{T}=\dot{\phi}_{L}+\dot{\phi_{S}}
$$

We can interpret Eq.(8) as defining a magnetic assembly in which there are three major flux paths. These general observations permit us now to sketch out a magnetic path arrangement that satisfies the needs of Eq.(8). This is done in Fig. 5.

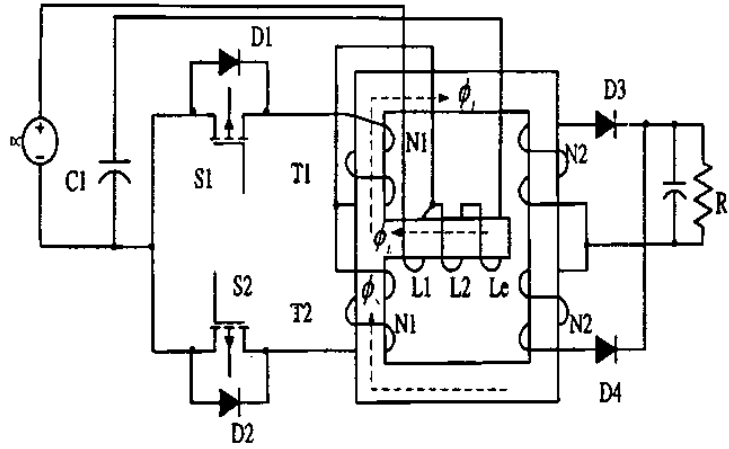

Fig. 5 The integrated magnetics of the proposed push-pull converter

\section{PROPOSED PUSH PULL BOOST CONVERTER}

This section mainly discusses the steady state and integrated magnetic properties of the proposed converter. It shows that the proposed boost converter has the same steady-state properties as the conventional boost converter.

\section{A. Principle of operation}

The principle of operation in steady-state condition is described with the following assumptions.

- All the switches and components are ideal.

- Transformers T1 and T2 are identical.

- Inductance L1 and L2 are tightly coupled with each other.

- The output voltage Vo is assumed to be constant.

1) Mode $1(\mathrm{t} 0<\mathrm{t}<\mathrm{t}$, $\mathrm{t} 2<\mathrm{t}<\mathrm{t} 3)$

With the switch $\mathrm{S} 1$ and S2 ON, the inductor $\mathrm{Ll}$ is grounded. Is is increased, resulting in energy stored in L1, Ir is increasing and then changes its direction. The diode D1 - D2 is not conducting during this period. The voltage across inductor $\mathrm{Ll}$ is the input voltage, Vin, and the voltage across inductor $\mathrm{L} 2$ is $\mathrm{Vcl}=\mathrm{Vin}$.

2) Mode $2(\mathrm{t} 1<\mathrm{t}<\mathrm{t} 2)$

With the switch S1 ON and S2 OFF, Ir releases the energy stored in Ll to the transformer $\mathrm{Tl}$. Ir is still keeping its positive direction, however, it is decreasing. The capacitor $\mathrm{Cl}$ is charged by Ir. The voltage across inductor $\mathrm{L} 1$ is (Vin-Vp). The voltage across inductor $\mathrm{L} 2$ should be $\mathrm{Vcl}-\mathrm{Vp}=\mathrm{Vin}-\mathrm{Vp}$.

3). Mode $3(t 3<t<t 4)$

With the switch S1 OFF and S2 ON, Ir releases the energy stored in $\mathrm{Ll}$ to the transformer $\mathrm{T} 2$. The converter action operates the same as mode 2 .

As a result, the inductances $L 1$ and $L 2$ have the same voltage waveforms during the whole cycle. The voltage relationships of Fig.6, along with the right choice of leakage inductances (Le) associated with the inductor windings, are the key factors in achieving zero-ripple current at the input of the proposed push-pull converter [8].

\section{B. Steady state analysis}

1) Voltage gain

According to the voltage-second balance

$\operatorname{Vin}(D-1 / 2) T s=(V p-V i n)(1-D) T s$

, where $\frac{V o}{V p}=\frac{N s 1}{N p 1}=\frac{N s 2}{N p 2}=\frac{1}{n}$

Thus, the following voltage gain can be derived

$M v=\frac{V_{O}}{V i n}=\frac{1}{2(1-D) n}$

Considering the power balance $\mathrm{Pin}=\mathrm{Po}$, that is Vin Is $=$ Vo Io

The current gain is

$$
M_{I}=\frac{l o}{I s}=2(1-D) n
$$

2) DC characteristics

From Fig.6, the average current of $i_{L 1}$ and $i_{L 2}$ can be derived as follows: 


$$
\begin{aligned}
& I_{a v L 1}=\frac{1}{4}(2 D-1) \frac{V i n}{L 1} T s+I \\
& I_{a v L 2}=\frac{1}{4}(2 D-1) \frac{V i n}{L 2} T s-I
\end{aligned}
$$

It can be seen that the presence of the capacitor implies that $\mathrm{I}_{\mathrm{avL} 2}=0$ in steady state. Leq and $\mathrm{K}$ are defined as follows :

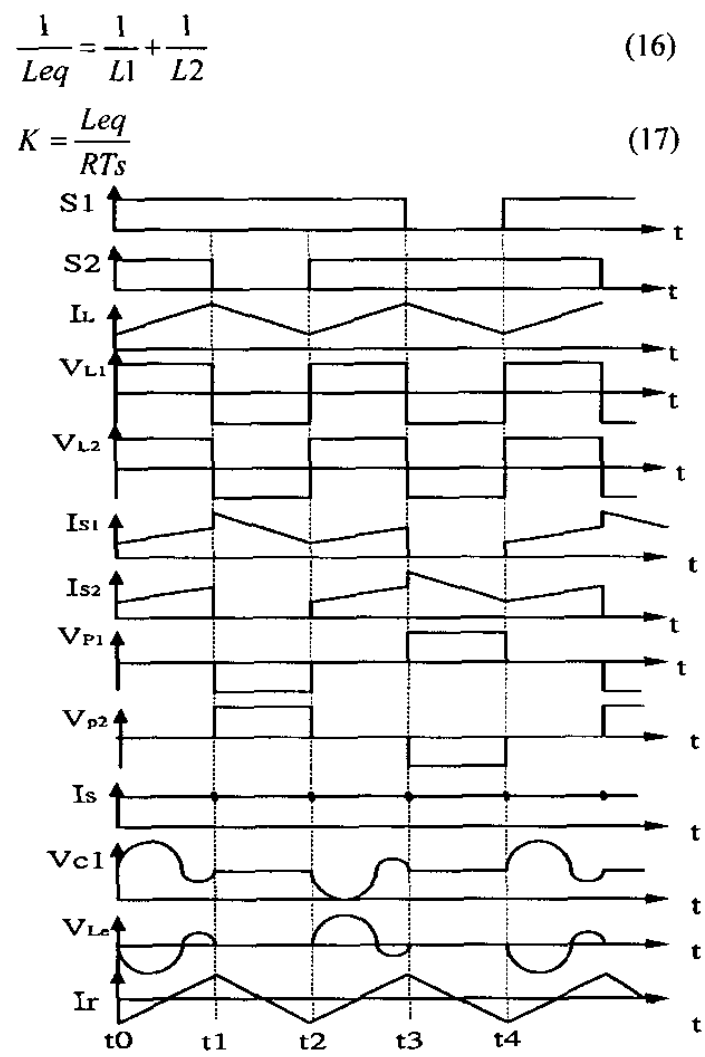

Fig. 6 Main waveforms of the converter in a switching cycle

The output average current flows in the mode 2 and mode 3 , i. e., when the diode is conducting. Therefore

$$
I o=\frac{n \text { Vin }}{2 \text { Leq }}(1-D)(2 D-1) T s
$$

Using the assumption of $100 \%$ efficiency, the average input current can be derived

$$
\text { Is }=\frac{\text { IoVo }}{V \text { in }}=\frac{n V o}{2 L e q}(1-D)(2 D-1) T s
$$

Summing $\mathrm{I}_{\mathrm{avL} 1}$ and $\mathrm{I}_{\mathrm{avL} 2}$

$I_{a v L 1}+I_{a v L 2}=\frac{V i n}{4 L e q}(2 D-1) T s$

$=\frac{n V_{o}}{2 L e q}(1-D)(2 D-1)$

An interesting equation can be derived $I s=I_{a v L 1}+I_{a v L 2}$

This means that the averaged input current is equal to the sum of the currents through the two inductors

Qualitatively, this must be true since $\mathrm{I}_{\mathrm{avL} 2}=0$

3) Boundary condition

Considering the power balance again, where

$P o=10^{2} R$

$P$ in $=I s \bullet V$ in

Thus

$\mathrm{n}^{2}(1-\mathrm{D})^{2}(2 \mathrm{D}-1)$ TsR $=$ Leq

then substituting (17) into (24), that is

$n^{2}(1-D)^{2}(2 D-1)=K$

It can be seen that continuous current mode can be achieved in the proposed topology. The boundary conditions are

$$
\begin{aligned}
& \frac{1}{2}<D<1 \\
& M>\frac{1}{n} \\
& K>0
\end{aligned}
$$

4) Semiconductor devices stress

The switch average current is

$$
\text { Iavs } 1=\operatorname{Iavs} 2=\frac{\text { VinTs }}{2 \text { Leq }}\left(D-\frac{1}{2}\right)\left(\frac{3}{2}-D\right)
$$

The diode average current is

$$
I_{a v D 3}=I_{a v D 4}=\frac{n V i n T s}{2 \text { Leq }}(1-D)(2 D-1)
$$

The switch peak current is

$$
i_{p k S 1}=I p k S 2=\frac{V i n T s}{2 L e q}(2 D-1)
$$

According the previous analysis, Fig. 7 shows some characteristics curves for the proposed converter.

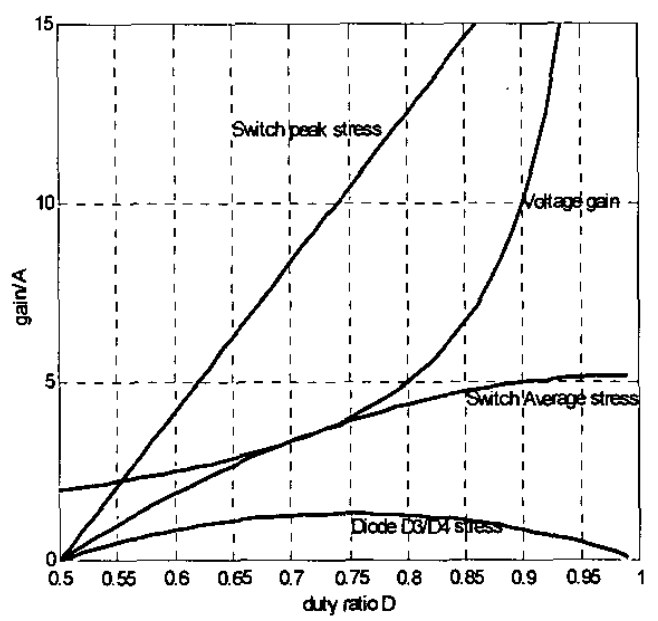

Fig. 7. Characteristic curves for the proposed converter.

\section{Derivation of the integrated magnetics}

A novel magnetic integration approach is proposed for the push-pull boost converter as follows. The current 
directions are defined as in the equivalent electrical circuit shown in Fig.8.

Fig.8 (a) shows the reluctance model for the proposed magnetic circuit. The electrical circuit model can be derived from the reluctance model by using the principle of duality, as shown in Fig. 8 (b). The circuit of Fig. 8 (c) results from scaling step with $\mathrm{Np}$ designated as the reference winding. The scaled permeances are then replaced by inductances. From the reluctance circuit shown in Fig. 8(a), the fluxes in the cores can be derived in the form of reluctances and MMF sources, as follows:

$$
\begin{aligned}
& \phi p=\frac{\mathfrak{R} c+\mathfrak{R g}}{\mathfrak{R} c(\mathfrak{R} c+2 \mathfrak{R g})} N p \cdot i p-\frac{\mathfrak{R} g}{\mathfrak{R} c(\mathfrak{R} c+2 \mathfrak{R} g)} N s \cdot i s \\
& \phi s=\frac{-\mathfrak{R g}}{\mathfrak{R} c(\mathfrak{R} c+2 \mathfrak{R g})} N p \cdot i p+\frac{\mathfrak{R} c+\mathfrak{R} g}{\mathfrak{R} c(\mathfrak{R} c+2 \mathfrak{R} g)} N s \cdot i s
\end{aligned}
$$

Where, $\Re c$ and $\Re g$ represent the reluctances of the outer and center legs, and ip and is are the total winding currents reflected to primary and secondary of the transformer, respectively. According to Farady's Law, and that the mutual inductance between $\mathrm{Lp}$ and $\mathrm{Ls}$ is $\mathrm{M}$, and coupling coefficient is $\mathrm{k}$, the relationship between inductances and reluctances can be derived as follows:

$$
\begin{aligned}
& L p=\frac{(\mathfrak{R} c+\mathfrak{R} g) N p^{2}}{\mathfrak{R} c(\mathfrak{R} c+2 \mathfrak{N} g)} \\
& L s=\frac{(\mathfrak{R} c+\Re g) N s^{2}}{\mathfrak{R} c(\mathfrak{R} c+2 \mathfrak{R} g)} \\
& M=\frac{\mathfrak{R} g N p s}{\mathfrak{R} c(\mathfrak{R} c+2 \mathfrak{R} g)} \\
& k=\frac{\mathfrak{R g}}{\mathfrak{R} c+\mathfrak{R} g}
\end{aligned}
$$

As can be seen from Eq. (35) and (36), in the proposed integrated magnetic structure, the coupling coefficient for the transformer is close to one. Two coupled windings still have a certain amount of leakage inductance. In practice, the reluctances from the magnetic material influence the value of $\mathfrak{M}$ and $\Re g$.

\section{EXPERIMENT RESULT}

The new push-pull boost converter was implemented, with the following specifications: output power $\mathrm{P}_{0}=80 \mathrm{~W}$; input voltage $\mathrm{Vin}=25 \mathrm{~V}$; output voltage $\mathrm{Vp}=35 \mathrm{~V}$; switching frequency fs $=200 \mathrm{Khz}$.

The switch conduction sequences of the proposed converter are shown in Fig. 9. It can be seen that the duty cycles greater than $50 \%$. The line current and line voltage are shown in Fig. 10. It can be seen that the ripple is almost zero. Fig. 11 shows the voltage across capacitor L1 - L2. It has the same wave. The corresponding line-current harmonics are shown in Fig. 12. The harmonic limits for IEC 1000-3-2 class D standard are also given in Fig. 12. It satisfies the standard with enough margins. The efficiency of the power stage of the converter is shown in Fig. 13. The maximum value at full load is $90 \%$.

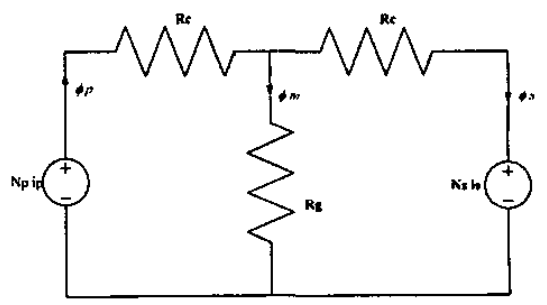

(a)

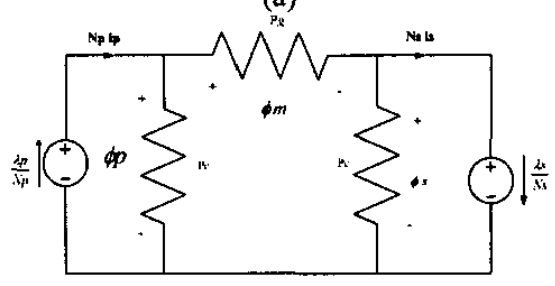

(b)

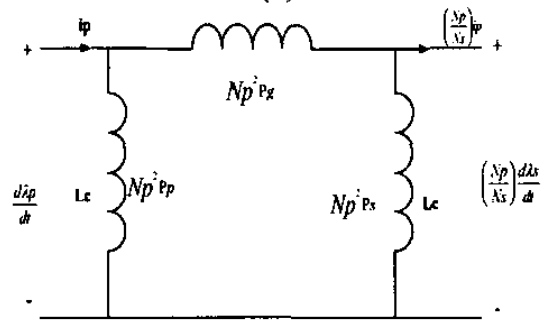

(c)

Fig. 8 (a) The reluctance model of proposed magnetic circuit (b) model (a) by using the principle of duality (c) model (b) of scaling step with $\mathrm{Np}$ designated as the reference winding.

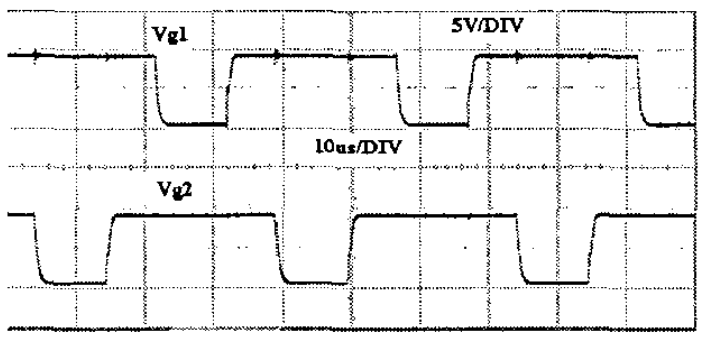

Fig. 9 Measured MOSFET gate voltage (Vgl, Vg2) waveforms.

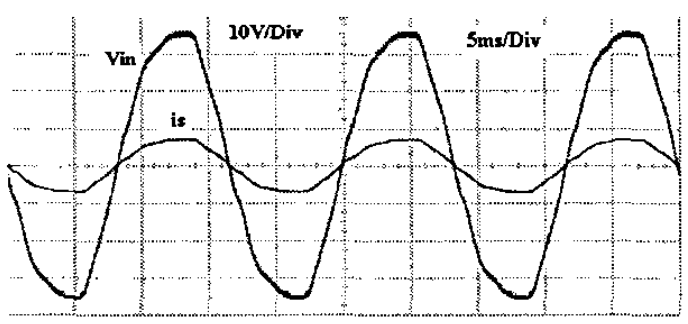

Fig. 10. Measured the line voltage (Vin) and line current (is) waveform with input current shaper 


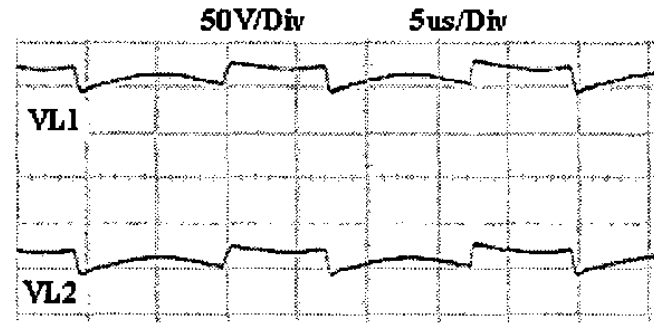

Fig. 11 Experiment results of the voltage across inductor

Normalized harmonic current

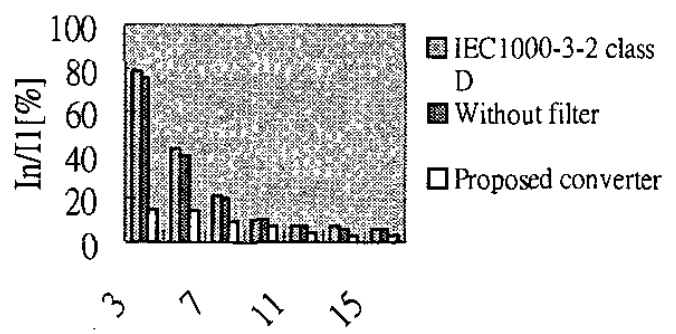

harmonic order

Fig. 12 The corresponding line-current harmonics.

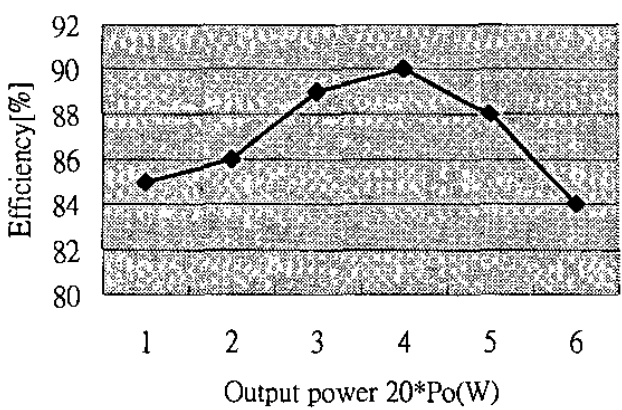

Fig. 13 The efficiency of the proposed converter

\section{CONCLUSIONS}

A novel simple single-stage push-pull AC/DC converter has been introduced. This converter can achieve small converter size and zero-input current using coupled inductor techniques. The proposed circuit is of simple topology and control strategy. It has several advantage such as lower switch and diode stress, lower stresses on capacitor $\mathrm{Cl}$. This makes the conduction and switching losses low and may result in a high efficiency. It is proved that the proposed boost converter has the same steady-state properties as the conventional boost converter. It is proved that the proposed boost converter has the same steady-state properties as the conventional boost converter. Blending of inductors and transformers of SPCs into single magnetic systems can be very advantageous, often resulting in converter designs of lower cost, weight, and size than their discrete magnetic counterparts. Conversion performance can also be improved and component stresses reduced, provided the integration process is well thought out and executed properly.

\section{REFERENCES}

[1] C. Qiao, and K. M. Smedley, "A topology survey of single-stage power factor corrector with a boost type input-current shaper," IEEE Trans. Power Electron, vol. 16, pp. 360-368, May. 2001.

[2] O. Garci'a, J. A. Cobos, P. Alou, and J. Uceda, "A simple singleswitch single-stage AC/DC Converter with fast output voltage regulation," IEEE Trans. Power Electron, vol. 17, pp. 163-171, March. 2002.

[3] L. Huber, and M. M. Jovanovic', "Single-stage single-switch inputcurrent-shaping technique with fast-output-voltage regulation," IEEE Trans. Power Electron, vol. 13, pp. 476-486, May. 1998.

[4] Q. Zhao, F. C. Lee, and F. Tsai, "Voltage and current stress reduction in single-stage power factor correction $\mathrm{AC} / \mathrm{DC}$ converters with bulk capacitor voltage feedback," IEEE Trans. Power Electron, vol. 17, pp. 477-484, July. 2002.

[5] L. Huber, J. Zhang, M. M. Jovanovic', and F. C. Lee, "Generalized topologies of single-stage input-current-shaping circuits," IEEE Trans. Power Electron, vol. 16, pp. 508-513, July. 2001.

[6] J. Wang, W. G.. Dunford, and K. Mauch, "Analysis of a ripple-free input-current boost converter with discontinuous conduction characteristics," IEEE Trans. Power Electron, vol. 12, pp. 684-694, July. 1997.

[7] J. Abu-Qahouq, and I. Batarseh, "Unified steady-state analysis of soft-switching DC-DC converters," IEEE Trans. Power Electron, vol. 17, pp.684-691, September. 2002.

[8] P. Xu, M. Ye, P. L. Wong, and F. C. Lee, "Design of $48 \mathrm{~V}$ voltage regulator modules with a novel integrated magnetics," IEEE Trans. Power Electron, vol. 17, pp. 990-998, November. 2002.

[9] S. Hamada and M. Nakaoka, "A novel zero-voltage and zero-current switching PWM DC-DC converter with reduced conduction losses ," IEEE Trans. Power Electron, vol. 17, pp. 413-419, May. 2002.

[10] C. M. Duarte, and I. Barbi, "An improved family of ZVS-PWM active-clamping DC-to-DC converters," IEEE Trans. Power Electron, vol. 17, pp.684-691, January . 2002.

[11] B. K. Bose, Power Electronics and AC Drives. Englewood Cliffs, NJ: Prentice-Hall, 1986.

[12] R. Severns, G. Bloom, Modern DC-DC Switchmode Power Converter Circuits. Van Nostrand Reinhold, N.Y.1985... 